\title{
Ecological Education System of University Students Honesty Education
}

\author{
Yansheng $\mathrm{Hu}$ \\ Hubei Normal University, Huangshi, 435002, China
}

\author{
Keywords: University Student, Honesty Education, Ecological System
}

\begin{abstract}
To carry on honesty education for the university students plays a major role in modern university students' quality education. In the constructive process of the ecological education system of university students honesty education, colleges all over the world should follow the principle of the organic combination of self-discipline and heteronomy, proactive learning and exploring the successful experience of western education in this aspect, and then to build the relevant ecological education system in the credit education of universities, optimize the growth environment of university students, promote the comprehensive qualities of university students.
\end{abstract}

\section{Introduction}

The ecological education system of university students honesty education is an important concept which is on the basis of ecology theory, in brief, that all the key element in the university students honesty education system, such as educators, educatee, education environment, education resources and others, will be the main creating structure of the ecological education system.The most basic composing state of honesty education system of university students in our country is the two main bodies of honesty education — the mutual connection and interaction in educational practice between educators and educatee. Therefore, the optimization of the ecological education system of university students honesty education should focus on the two aspects. For the actual need of the two aspects in honesty education, we should develop some measures on the basis of ecology theory to establish a strong ecological education system, create conditions for the promotion of university students honesty education level.

\section{The importance of honesty education for university students}

At present, under the influence of the infaust factor in the market economic system, the credit problem of university students in our country is becoming more and more serious, which has a bad influence on the overall quality of students. On the basis that the society has realized the importance of honesty education in our country, all the colleges and universities should further enhance the degree of recognition for university students honesty education, and take some measures to strengthen the practical level of university students honesty education under the guidance of ecology. The practice has proved that it is necessary to emphasize and pay attention to the university students honesty education in our country. It is the inevitable requirement of the socialist market economic system in the future development process. It is also the practical need that the educational circles in our country cultivate high-quality talents to meet the needs of social modernization construction.

\section{To strengthen the emphasis on university students honesty education is an important preparation for promoting the full development of university students}

Honesty is always considered as the traditional virtue of the our nation in the thousands years of civilization development, and a basic social ethics, but also the essential features in building a harmonious socialist society for our country ${ }^{[1]}$. If the university students want to promote their full development, they should use honesty as the starting point for the activities in the learning life, take certain steps to strengthen the cultivation of their own moral qualities, and take the initiative to practice the good faith. At the time of the unceasingly deepening of today's social reform and opening up, only on the basis that the university students study hard scientific and cultural knowledge, 
enhance their professional quality, to strengthen honesty education, can they really promote their comprehensive development, and make a greater contribution to the cause of socialist modernization.

\section{It is the inevitable requirement to promote the coordinated development of socialist market economy}

The honesty education for the university students in our country can have a very important influence on the healthy development of the socialist market economy. University students as the important participant and successor of socialist construction in our country, the level of honesty quality will have a decisive influence on the healthy and orderly development of the socialist market economy. At the same time, in the perspective of social ethics, the dominant role that moral personality plays on human individuals determines the individual's moral behavior habits in a certain extent , not only provide a certain degree of support for the moral behavior habits of individuals in social life, but also determine the direction of the individual's moral development and the ultimate purpose of behavior in a certain extent, .

\section{It is the foundation to further promote the rapid and stable development of socialism with Chinese Characteristics}

Socialism with Chinese characteristics is the combination of the basic principle of Marxism and the basic national conditions of China in different historical period. The rapid and stable development of China needs a large number of talents with high professional quality and moral quality. University students are the pillars to support the future development of society. Therefore, as the successors to the cause of socialist construction, university students needs a relatively high quality of credibility

and morality ${ }^{[2]}$. In the process of socialist construction in the future, on the basis of the special condition of Chinese socialist construction, university students will have to face numerous difficulties and obstacles, under the background of the society, university students only use honesty as a weapon in the face of difficulties, do not forget your initial determination, then you can truly promote the steady and rapid development of socialism with Chinese characteristics.

\section{Conditions of creating the ecological education system of university students honesty education}

\section{Essential condition}

The essential condition for the formation of the ecological education system of university students honesty education in our country is the three-dimensional intercourse activity. The main factors that promote the formation of the ecological education system of honesty education are the teachers who are in the position of the educator, students who are in the position of the educatee and the parents of students, and there is a relatively harmonious relationship between teachers and students, parents and child. Each subject on the premise of mutual communication at university education level, transmit their own integrity education ideas and the results of learning by the ways of the application carrier of honesty education or method, the educators evaluate students' learning results according to the students' communication and daily performance, and feedback the results to the students timely, in order to get better effect of honesty education .

\section{Sufficient condition}

The sufficient condition for the formation of the ecological education system of university students honesty education is simply a virtuous nutrition cycle, specifically on the basis of the necessary condition of three-dimensioned associating, to promote the communication and exchange of the continuous energy, information and the biomass between different components in the ecological education system, according to the trophic relationships of primitive ecological system of nature, combined with actual needs of our country's university students honesty education at present, build a targeted nutrient cycling of the ecological education system of honesty education ${ }^{[3]}$. In honesty education, communication and exchange between the various related subjects can not only 
realize their own value in the process, but also produce a positive interaction effect in the nature through scientific nutrition cycle, which will have a positive influence on the promotion of the culture level of social whole.

\section{Countermeasure of optimizing the ecological education system of university students honesty education}

\section{Attach importance to the coordinated development of self-discipline and heteronomy}

First of all, university students should be "cautiousness" in learning and life, gradually shaping healthy personality. In our country's traditional cultural thoughts, cautiousness is a kind of high consciousness and a spiritual expression of the unity of moral knowledge and practice in living practice. University students should develop the habit of life honesty and trust of self-supervision and self-discipline in honesty education, avoid dishonesty on the spiritual plane, promote their integrity accomplishment in the self-critical and ideological struggles. Second, the honesty and credit education of universities and colleges can have the aid of heteronomy to constrain college students' behavior, to further improve the living environment of the college students. Traditional credit education in colleges and universities generally takes into infusion education as the main, the practice education of moral behavior has been neglected, which has a negative impact on the cultivation of students' integrity. So university teachers should change the traditional concept of education, to exemplified the lofty paragons of credibility for the students, and in all aspects of student management work to gradually establish a good faith education and efficient, honest heteronomy management for the students. Finally, colleges and universities can also establish a corresponding credit incentive system according to the actual need, to ensure that the resume writing and diploma level of university students are able to get the appropriate credit guarantee. All in all, in the students education management work, universities should establish a sound and a strong operability of the ecological education system of university students honesty education, to provide the corresponding support for the honest improvement of their accomplishment of college students.

\section{The idea of infiltrating the honesty education into the campus culture construction has created a credibility culture atmosphere}

To construct the ecological education system of university students honesty education, we should optimize the ecological environment of college students credit education, make full use of the potential impact of the ecological environment to the university students, and take the construction of campus culture as the carrier, create conditions for the improvement of university students' credit quality.

To strengthen the construction of university campus facilities

University campus is the basis place of the daily life of university students, which has a subtle influence on the development of students' personality ${ }^{[4]}$. Therefore, under the guidance of ecology theory, it should be combined with the actual development of colleges and universities, establish a high level of ecological, landscape campus environment in alternative, so that every part of the campus environment has become the communication carrier of the grand spiritual civilization, and then to have a subtle influence on the students, help and guide students to develop the basic quality of life honesty and trust.

To strengthen the construction of the soft environment of campus culture

In the current university campus of our country, the school spirit, the school motto, and other symbols on behalf of university culture are produced by colleges and universities in the development of long time accumulated in the spirit, which is the cream of thoughts, reveal the truth, goodness and beauty of connotation in a certain extent, that can make a corresponding positive influence on university students' spiritual growth. Therefore, in the construction of the ecological environment of the campus, to create the integrity atmosphere of study and life for the students through the school spirit, the school motto, and encourage students to gradually develop a rigorous and pragmatic 
working style, create excellent conditions for the cultivation of integrity quality of college students. Honest atmosphere of the campus culture is closely linked to targeted and scientific ethos, the motto education of colleges and universities, the school spirit and motto with a higher ideological level can guide students to consciously accept the sincere thought of penetration and assimilation through an invisible force, so as to lay a foundation for the cultivation of college students honesty credit quality.

Launch scientific campus credibility education activities actively

Under the influence of the ecological theory, the effect of college credibility education are increasing visible, but the credibility education itself is also more complex.To optimize the ecological environment of college students' credibility education, the ideological and political education workers should attach greater importance on the campus credibility activities, and make full advantages of campus resources, to improve the honest accomplishment of college students. In the actual development of the campus credibility activities , the most important point is supposed to pay attention to the way of propaganda innovation, through the activities of setting the corresponding signatures of integrity "," unmanned invigilation ", to urge students to adhere to the principle of good faith in the related activities, to enhance the effect of honesty education ${ }^{[5]}$. At the same time, in the university entertainment activities and the corresponding scientific research activities, sincerity idea should also fully and thoroughly implemented, the campus network platform and the broadcasting platform can be properly exploited, to carry out the good faith propaganda in the campus, ensure that students can receive the appropriate credit education in different kinds of educational activities, and improve their credit quality.

\section{To build joint forces of honesty education from society, school and family}

A person's own moral quality is closely related to the living environment. University students as a social person, their own integrity character is also linked to the social environment, school environment and family environment. Among them, the school is the main position to carry out the honesty education, which should take the initiative to take on the important task of cultivating the students' good faith quality. At the same time, college student is the individual of the society in social life, therefore, a good social customs can also have an extremely important influence on the ideological and moral quality of university students. Once the integrity thought they met with in society differs from the school education, they will throw doubt upon the school education on the basis of their own judgment, which will influence the practical effect of honesty education in colleges and universities. However, the cultivation of good social customs is a long-term project, the current society is in transition and development, the social must strengthen the emphasis on honesty-credit moral education of college students, and manage the problems of losing-credit in society timely, and gradually form a good atmosphere of honesty and trustworthiness. Family is a small element in the whole society, in the family life, good family atmosphere also will have a positive impact on the students' good faith. For example, that the elders keep the marriage vows can strengthen the students' understanding and comprehension of marriage, and then form a good quality, which will play a role in the formation of their comprehensive and social harmony and stability.

\section{Learn from foreign advanced credit education experience}

Moral education is a problem concerned by education circle not only in China, but also in the world. Einstein attaches great importance to the integrity of moral education, that is, only the person with a high degree of integrity can bring whole human society to a happy life. But in the past few years the investigation for honesty of the world's college students have shown that almost half of the students do not deny that they have ever cheated in exams. The problem of credit crisis of college students has gradually developed into a global education problem. The study of the credibility education started early in western developed countries, and now it have had a preliminary research results. For example, colleges and universities can combine with the actual situation of the school to set up the corresponding integrity education file of university students, and ensure that the file will be lifetime effective, to lateral urge students to consciously practice the integrity of the idea. The study of university students honesty education is very evident in United States, as early as the late 20th 
Century, the United States education researchers have begun to focus on the dishonest behavior in college students' examination , and after the investigation, the university education institutions should be combined with their own social core values as well as the essence of traditional culture, and build ecological integrity campus environment actively, to provide good faith education space for the students.

\section{Conclusions}

The construction of the ecological education system of university students' honesty education is not only beneficial to the purification of students' ideas, but also to improve the students' integrity and quality. It also has a positive impact on the construction of socialist spiritual civilization and the harmonious and stable development of the society. Therefore, in order to further improve the level of integrity education of college students, the educators of ecological education system should set an example, and learn from foreign advanced experience, under the effect of the harmonious relationship between teachers and students, parents and child, to provide a support of an excellent ecological education system for the college students.

\section{References}

[1] Liu Jing. Analysis on the formation mechanism of the ecological chain of the integrity education of college students.Jiangsu Higher Education, 2011, 01(5):116-117

[2] Qin Lin, Luo Zonghuo. Study on the ecological environment of college students' honesty and integrity.Social scientist, 2012(12):58-61

[3] Wang Lanlan. Views on strengthening and improving college students' honesty education in higher vocational colleges. Management Observer, 2013(1):60-61

[4] Li Hong. Problems and countermeasures of higher vocational students in honesty education. Management Observer, 2012(31):95-96.

[5] Wang Yang. New discussion on the contemporary college students' honesty education. Intelligence, 2015(17):191-191 